\section{O lado onírico da ciência ${ }^{1}$}

\section{RESUMO}

A autora tece eflexões sobre nossa condição de construtores de sonhos, vivendo permanente o limite entre 0 sonho bom $e$ o pesadelo, entre a "boa e a má utopia" (Morin).

\section{ABSTRACT \\ The author reflects upon our condition of dream makers, living permanently in the limit between de good dream and the nightmare, or else between "the good and the bad utopy" (Morin). \\ PALAVRAS-CHAVE (KEY WORDS) \\ - Cultura (Culture) \\ - Sociedade (Society) \\ - Ética (Ethics)}

SentAdo DIANTE do mAR, um grupo de crianças se empenha em construir castelos de areia. As crianças sabem bem que há um lugar ideal para que as edificações não desmoronem rapidamente. Esse lugar está no meio do caminho entre a areia muito seca e as últimas ondas que deitam constantemente na praia.

O conjunto arquitetônico que congrega os castelos, exibe muralhas, diques, torres de observação, subterrâneos, alamedas.

Para construir um complexo de tal monta é necessário competência, intenção, desejo, atitude. Só se edificam castelos na areia se as mãos se tornam veículos de onde flui criatividade capaz de transformar areia em castelos.

Sentadas diante do mar essas crianças cumprem a função de nos relembrar o ritual da vida em sociedade. Construtores de sonhos, veículos de desejo, esta é a síntese da condição humana. Fazedores de castelos de areia. A única espécie viva que sonha acordada, como nos lembra Edgar Morin. Nada a estranhar, uma vez que, conforme Shakespeare, "somos feito da mesma matéria que são feitos os sonhos".

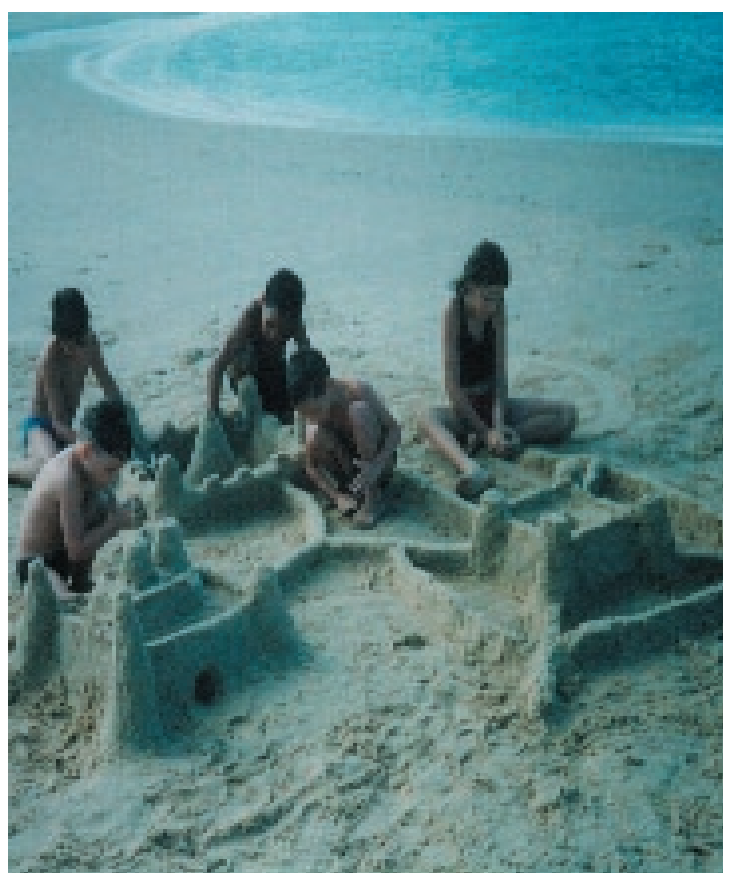

Maria da Conceição Xavier de Almeida ${ }^{2}$

Professora da UFRN 
Castelos de areia Foto: Eugênio Soares

Acredito que a história de crianças que constroem castelos de areia fornece um conjunto rico de imagens para discorrer nesse artigo, sobre o que escolhi para apresentar e discutir com vocês.

De uma forma ou de outra, advindos de pertencimentos diferenciados, imbuídos de tarefas cotidianas diversas, constituídos por singularidades psíquicas preciosas, todos nós reatualizamos no nosso tempo o ritual próprio aos construtores de sonhos.

Por vezes, as muralhas escondem os castelos. Outras vezes os diques são demasiadamente fortes e permanentes, e, ao invés de nos proteger da erosão e do assoreamento, esses diques e muralhas nos impedem de ensaiar qualquer improviso e criatividade, ou, ainda, fuga para outros horizontes - sejam eles teóricos, pessoais ou sociais.

Alguns grupos de construtores de sonhos esquecem de multiplicar as alamedas que ligam os castelos entre si, e então ficamos ilhados em nossos próprios porões. Isso quer dizer que nem todo sonho opera confluência, encontro, multiplicação. Há bons sonhos, mas também sonhos sofridos a que chamamos pesadelos.

Os construtores de sonhos, que somos nós, vivemos permanentemente o limite entre o sonho bom e o pesadelo, nas palavras de Edgar Morin, entre a "boa e má utopia".

É a partir desse patamar que tentarei problematizar algumas questões que julgo importantes para pensar a cultura, a sociedade que vivemos e a sociedade que queremos construir, e, por fim, para propor uma ética do pensamento, capaz de sonhar por nossas próprias mãos, uma prática social que faça jus e merecimento ao que há de mais complexo e mais precioso na nossa contingência de sapiens-sapiensdemens: sonhadores de bons sonhos.

Castelos de terracota
Outras variações de terra têm servido como matéria-prima para os fazedores de sonhos. $\mathrm{Na}$ antigüidade grega, pequenas estatuetas

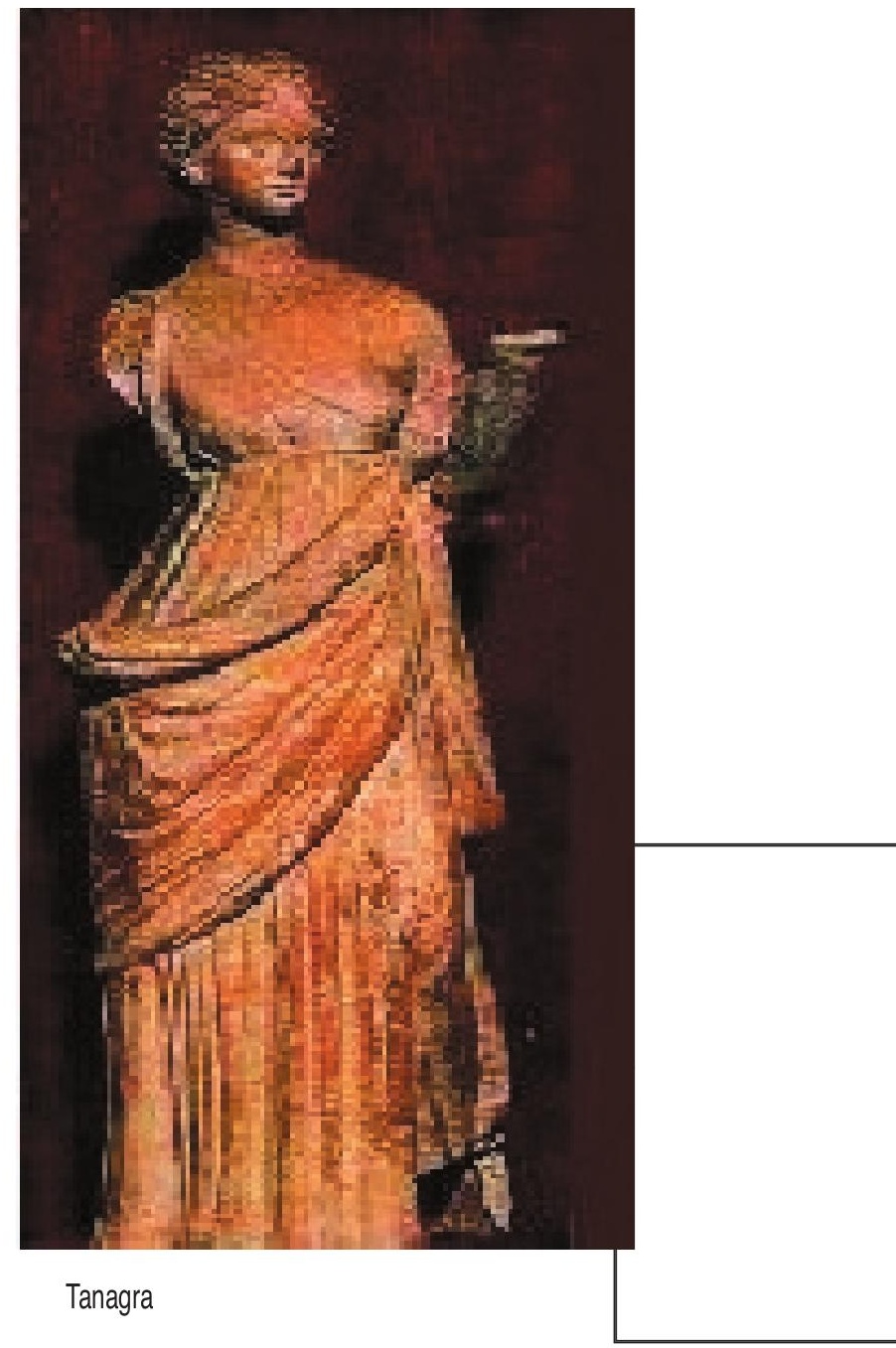

- Tanagra, Tanagrine - eram esculpidas em terracota e ficaram famosas pela perfeição de suas formas. Esse artesanato é originário da cidade do mesmo nome (Tanagra, na Beócia). A terracota é um tipo de barro ou argila que, mantidas as possíveis variações de textura, coloração ou outras decorrentes da idade geológica, ou do meio onde se encontra, é o mesmo barro no qual se esculpem os ex-votos e que servem também para a construção das casas de sapê comuns no Nordeste do Brasil. $O$ bom artesão sabe bem que a durabilidade de sua arte - seja uma minúscula estatueta, uma parte do corpo transformada pela liturgia em ex-voto, ou uma casa de sapê - não depende exclusivamente da terra apropriada. 
O ponto certo da umidade, a compactação correta (sempre a meio-termo entre o cristal e a fumaça), o retoque, bem como o cuidado e o zelo, são investimentos importantes para a durabilidade do sonho tornado matéria.

Esse desmembramento da primeira metáfora - castelos de areia - nos ajuda a pensar a cultura, o conhecimento e a ética que temos construído enquanto humanos, ao longo dos séculos. Não vou me deter no longo diagnóstico que nos trouxe até aqui. Mesmo assim, interessa aludir ao fato de que talvez não tenhamos conseguido dar boa textura e contornos adequados aos sonhos bons. Talvez não tenhamos conseguido materializar as boas utopias. Certamente, parte dos bons sonhos foi usurpada, roubada, inibida ou impedida de acontecer em profusão. A sociedade que nos foi legada, e que continua em construção, é o produto da dialógica permanente entre o bom sonho e o pesadelo, entre a boa e a má utopia. Entretanto, se podemos diagnosticar a dinâmica e o formato perverso, injusto e desigual da sociedade atual; se é possível dizer que a fragmentação do conhecimento é enormemente responsável pelos graves problemas de ordem ecológica e social do nosso tempo, podemos igualmente afirmar que vivemos um momento crucial de avaliação e de tomada de consciência dos limites a que chegamos. $E$ isso é bom. Fritjof Capra sintoniza esses limites em três eixos: a proximidade do fim das reservas naturais, a crise do patriarcado como modelo social e uma crise generalizada de valores. $\quad E d g$ a $r$ Morin e llya Prigogine acentuam que a cisão entre a cultura científica e a cultura humanística tem operado a inadequação entre conhecimento e mundo. David Bohm acentuou que um "jogo falso da mente" produz uma visão equivocada da realidade e impede o diálogo. Para Jöel de Rosnay, estamos de mãos atadas se quisermos construir a sociedade futura com base nos cálculos tendenciais do passado e do presente, e isso no tocante a qualquer fenômeno. Para ele, temos que nos valer de uma visão macroscópica e mais especificamente de um método retroprospectivo para imaginar e fazer acontecer a sociedade que queremos. Fatos portadores de sentido são os ingredientes que precisamos procurar e eleger como focos criadores de uma nova gestão societal. E, sejam quais forem os fatos portadores de sentido que elejamos, é fundamental que operemos uma atitude analógica e simbiótica com a dinâmica da vida que não se restringe ao propriamente humano, mas antes se difunde por todo o planeta Terra, pelo menos.

Nesse momento crucial e positivo de avaliação de como temos pensado e lapidado o mundo que vivemos, Edward Wilson também nos provoca e incita a fazer uma autocrítica da ciência. Originalmente especialista em formigas, Wilson, para quem "todos os cientistas, incluindo Einstein, são filhos de Tântalo, frustrados pela incapacidade de capturar o que parece ao seu alcance", nos chama atenção para o fato dos limites e possibilidades da biologia fundamental que unifica todas as espécies vivas.

Para ele, os cientistas sociais são biofóbicos; os biólogos sociofóbicos. O encantamento Jônico, expressão que toma de empréstimo a Gerald Holton, e que significa "a crença na unidade das ciências - uma convicção bem mais profunda do que uma mera proposta de trabalho", desemboca na noção de Consiliência, defendida por Wilson como "a chave" para a unificação do conhecimento científico. Antonio Damásio, um neurobiologista que desenvolve suas pesquisas buscando explicitar "o erro de Descartes", argumenta que é o mesmo cérebro e a partir dos mesmos mecanismos neuronais que se explicitam o que convencionamos chamar de razão e de emoção. E se outras investigações de outros neurobiologistas, como Oliver Saches (com a hipótese da plasticidade neuro-cerebral), nos 
permitem reproblematizar a dialógica antes inconcebível ou difícil de admitir entre intelecto e emoções, é em Edgar Morin que vamos encontrar com maior vigor uma reorganização do conhecimento que hipotesia o parasitarismo mútuo (não a indistinção), o intercâmbio permanente (não a unificação) entre pulsão, razão e emoção. Para Morin, reafirmando as investigações de Mac Lean, o cérebro humano, além de bi-hemisférico, comporta uma face triúnica. Três feixes de informação, dois dos quais precendem no tempo o sapiens-demens, coordenam a dinâmica de nossa comunicação com o mundo: o primeiro, propriamente reptílico (cio, agressão e fuga), o segundo, de origem mamífera (afetividade), e o terceiro, mais especificamente humano, caracterizado como neo-córtex (inteligência lógica e conceitual). É a partir do intercâmbio, entre esses três feixes de informação que vemos, pensamos e agimos no mundo. Longe de um ponto de equilíbrio e de harmonia, quase sempre, temporariamente, um desses pólos se sobrepõe aos outros, e nos defrontamos no nosso cotidiano com comportamento e atitudes (individuais ou coletivas) que exibem, por vezes mais acentuadamente, nossos aspectos pulsionais ciáticos ou agressivos. Outras vezes nossas aptidões de acolhimento e afetividade se sobrepõem e reorganizam a trindade cerebral. $E$ ainda, por vezes é a inteligência lógica e a razão que prevalecem como expoente maior. Esse argumento que sumariamente apresento para expor a dinâmica do processo cognitivo aparece na obra de Edgar Morin extremamente matizado e complexo. Penso que é a partir de matrizes como essa que ele pôde desenvolver a idéia de uma psique do conhecimento, conforme explicitado no método III. Os mecanismos de transferência de valores e de padrões de escolha social, e mais especialmente as instituições educacionais, jogam aqui um papel importantíssimo na produção e lapidação dos construtores de sonhos, do sujeito cognoscente. Seja por que somos coagidos de forma explícita, ou instigados de forma subliminar, temos, ao longo de nossa história, feito opções excessivamente excludentes e mutiladoras. A fragmentação que gerou a incomunicabilidade entre os saberes é um desses exemplos. No nível individual, as identidades forjadas reduzem o largo espectro dos vários pertencimentos que nos configuram como seres em constante metamorfose e construção. No panorama científico, a depender sempre da relação entre o pensador/sua psique e a sociedade/psique coletiva, tem-se operado, em algumas teorias e em certos períodos históricos, a hegemonia da razão e argumentado a favor da dissociação entre intelecto e emoção. Um tal argumento, que se torna cada vez mais insustentável e carece de rigor, alimentou por muito tempo o paradigma da separação entre ciência, filosofia, arte e literatura.

Vivemos hoje um momento fecundo de reaproximação e reencontros. Em relação ao reencontro entre a razão científica e a narrativa literária, Simone Vierne afirma: "A ligação tempestuosa entre ciência e literatura está a ponto de se tornar uma história de amor". Vierne, sem se perder no labirinto da racionalização argumentativa, dirá também que a diferença entre ciência e literatura "está unicamente na qualidade da pessoa que tomou a si o encargo de 'dizer' a visão do mundo, e isso constitui de fato um fenômeno novo... um fenômeno extremamente encorajador". O astrofísico Hubert Reeves, comentando o distanciamento entre cientistas e literatos, faz eco às palavras de $\mathrm{E}$. Wilson quanto à biofobia dos cientistas sociais e a sociofobia dos cientistas naturais, as quais já fizemos alusão: "Penso", diz Reeves, "que é importante chegar a uma harmonia entre ciência e literatura. Os literatos tendem demasiadamente a pensar que a ciência é enfadonha, e os cientistas que a literatura não é coisa séria". Freeman Dyson, físico inglês, é ainda mais incisivo na defesa da contaminação imaginal na 
ciência. "Para mim, a máquina do tempo de Wells dá mais insight sobre mundos passados e futuros do que qualquer análise estatística, pois o insight exige imaginação". Ou ainda: "Descobri que a ficção científica é mais esclarecedora do que a ciência para compreender como a tecnologia é vista por pessoas situadas fora da elite tecnológica. A ciência proporciona o imput técnico para a tecnologia; a ficção científica nos exibe o output humano".

A lista de pensadores oriundos de diversas áreas do conhecimento que têm se posto a re-modelar os antigos castelos de areia em ruína, ou se dedicado a cuidar das cicatrizes abertas e das fendas nas minúsculas estatuetas de terracota - castelos e tanagras que uso aqui como metáforas da ciência -, certamente pode ser enormemente acrescida. Faço apenas mais algumas referências, antes de iniciar o terceiro momento deste artigo.

Falo agora de uma mulher. A começar pelo nome do seu livro, A dança da terra, a bióloga grego-americana Elisabet Sahtouris nos incita a, como ela, fazer dançar nosso pensamento em busca de uma compreensão mais simbiótica e harmônica com a natureza da qual faz parte. É inadequado e impreciso, para E. Sahtouris usar a expressão "vida na Terra", e isso por dois motivos: primeiro, porque a Terra não é uma matéria inanimada e morta que abriga a vida; a Terra é viva. Segundo porque nós não somos desligados da Terra que nos abriga, somos mais propriamente uma porção, um pedaço da "vida da Terra". No livro citado a explicitação dos fenômenos físico-químicos, da dinâmica dos sistemas vivos, do comportamento do DNA, etc., tem a forma de um tecido que rejunta, sem discriminação hierárquica, os argumentos tecnocientíficos e aqueles de natureza ecológica e política, que são por sua vez indissociáveis das narrativas indígenas. Uma ciência militante e poética, alimentada pelo sonho de "salvar a humanidade", nas palavras de Sahtouris.

No mesmo tom de plasticidade está o investimento do astrofísico brasileiro Marcelo Gleiser. Dessa feita, trata-se da $(A)$ dança do universo. Para discutir questões como o "big-bang", o "vácuo quântico", em suma, as hipóteses sobre a origem do universo, Gleiser recorre aos mitos gregos (aos de origem), para fazê-los dialogar com os construtos científicos, em busca de uma narrativa da ciência que seja capaz de compreender, e, acima de tudo, de dialogar com as múltiplas configurações dos saberes primordiais. Para ele, "a natureza jamais vai deixar de nos surpreender. As teorias científicas de hoje, das quais somos justamente orgulhosos, serão consideradas brincadeiras de criança por futuras gerações de cientistas". As últimas palavras do livro "A dança do universo" denotam o quanto de emoção, de sentimento e de partilha e da experiência do êxtase está contaminado o processo cognitivo verdadeiramente criador. "Em graus diferentes, todos nós fazemos parte dessa aventura, todos podemos compartilhar o êxtase que surge a cada nova descoberta; se não por intermédio de nossas próprias atividades de pesquisa, ao menos ao estudarmos as idéias daqueles que expandiram e expandem as fronteiras do conhecimento com criatividade e coragem intelectual. Nesse sentido, você, eu, Heráclito, Copérnico e Einstein somos todos parceiros da mesma dança, todos dançamos com o universo. É a persistência do mistério que nos inspira a criar".

Inspirados por M. Gleiser, podemos dizer que somos todos parceiros na construção dos castelos de areia e é a persistência da pulsão cognitiva que nos incita a procurar o lugar e a terra adequados para construí-los e reformá-los. A ciência é um desses castelos que ao longo dos tempos temos edificado, reconstruído. Em alguns momentos suas pesadas muralhas ruíram. São então revogadas e perdem efeito certas interpretações do mundo. Grandes "brechas" se interpõem ao pensamento. Como sobreviver ao enigma do silêncio que se segue a uma pergunta sem resposta? 
Perplexos no primeiro momento, somos levados em seguida a refletir sobre a textura das muralhas: elas precisam ser porosas, refratárias.

Talve z nem precise de muralhas $3 / 4$ uma cerca viva, verde, cumpre bem a função de anteparo, de meia proteção contra algum predador ou uma onda mais forte. Noções mais que conceitos, argumentos abertos mais que dogmas, uma atitude mental metafórica mais que uma estratégia metonímica, se constituem, parece, em circunstâncias atenuantes para o desmoronamento em bloco do conhecimento, das mundovisões e das explicações científicas. A convicção de que toda matéria muda e está em movimento é também um antídoto importante contra a cristalização e a ossificação do pensamento e do conhecimento. Como sonhadores de bons sonhos, podemos construir nossos castelos num lugar mais adequado. O lugar mais adequado é o caminho do meio, entre a razão e a emoção, entre a prosa e a poesia.

Falando da perversa e inútil separação entre mito e razão, Michel Serres descreve assim o momento do reencontro entre os dois: "Então, cansado de sofrer, cada um abre os braços, como faziam outrora os suplicantes, e cada mão encontra uma mão a sua esquerda e outra a sua direita". Sonhando com um projeto que transforme a ciência em um protocolo de esperança, dirá G. Durand: "Mais do que nunca, sentimos que uma ciência sem consciência, ou seja, sem afirmação mítica de uma esperança, marcaria o declínio definitivo de nossas civilizações".

\section{Horizontes de fuga: abraçar}

Dietman Kamper conta-nos que de fato Adão e Eva não foram expulsos do paraíso. Eles fugiram de lá porque o paraíso era muito chato: era o reino da repetição e da ordem. Fala também Kamper de uma certa estatística do número de cadeiras por habitante do nosso planeta. Diz ele que, mesmo consideradas as populações para as quais inexiste esse objeto, a relação é de quatro cadeiras para cada habitante da Terra. Vivemos grande parte do nosso tempo sentados. Nos tornamos, às vezes, imobilistas.

A ciência é tida para grande parte da sociedade como uma coisa chata, um discurso da repetição, da ordem, da inércia. Como atores da história do nosso tempo, temos ficado muito no palco, quando é na coxia que as coisas acontecem fora do padrão esperado. Temos sobrevivido demais e vivido de menos. É preciso oxigenar as teorias, respirar.

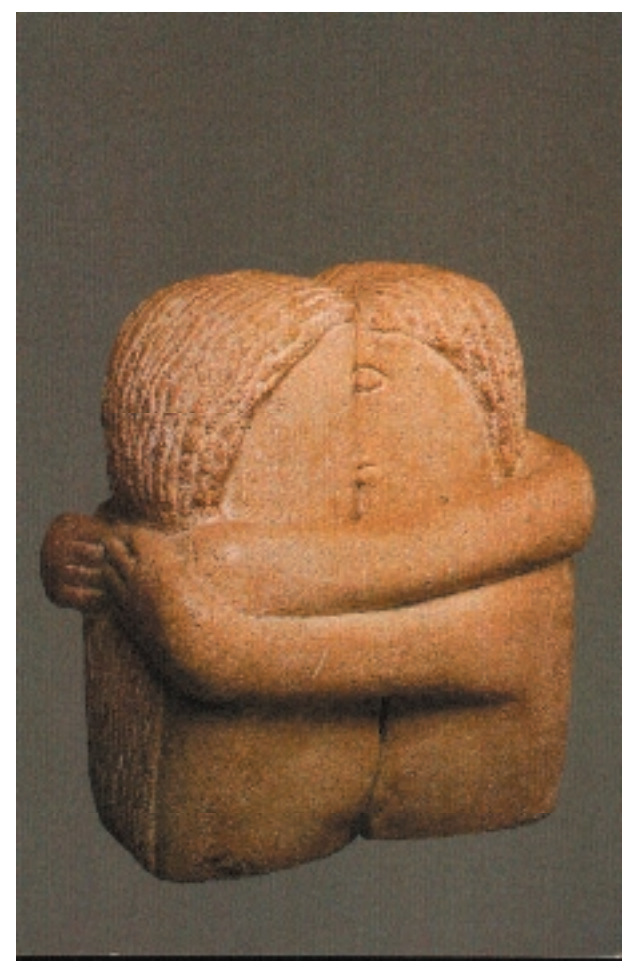

Le Baiser - Constantin Brancusi

Se o lugar da respiração da ciência deve ser o caminho do meio entre a imaginação e a razão, o lugar da transposição poética dos fenômenos, o lugar que transforma o "sobreviver" em "viver", como quer Edgar Morin, esse lugar requer um construtor capaz de investir na emoção ao mesmo tempo como uma ferramenta cognitiva, um argumento e um estilo de vida.

Daí por que, assim como a umidade 
da terra ajuda a manter por mais tempo de pé nossos castelos de areia - quer dizer, permite um diálogo mais fecundo e duradouro entre as enunciações da ciência e os fenômenos dos quais fala e com os quais dialoga -, também é necessário umedecer as palavras.

Umedecer as palavras é escolher a melhor composição química da saliva, que permite ao mesmo tempo a sonoridade e a dança dos discursos que criam, dos conceitos que fazem nascer, da compreensão do mundo que faz viver e nunca mata.

Umedecer as palavras é saber dosar a melhor argila, que é sempre a argamassa entre a areia mais seca (inteligência lógica e racional), a terracota mais condensada (o cimento mitológico de que fala LéviStrauss) e a areia mais molhada (a pulsão cognitiva e o insight proveniente da emoção).

É necessário ensaiar uma ciência da complexidade que rejunte e faça dialogar as várias dimensões da matéria, do sujeito do conhecimento, da cultura. É necessário evitar que o desespero diante de nossa condição de mortais provoque surtos de imortalidade do pensamento.

É necessário nos tornarmos ambidestros, conforme sugere Serres; lançar mão dos estoques imaginários como um "discurso de transferência e de amor" (Julia Kristeva).

É necessário projetarmos espaços de fuga para além das muralhas conceituais, teóricas e metodológicas que interditam a visão de horizontes maiores, mais plenos, mais perigosos, mais criativos. Isso é devolver a vida à ciência, para além da sobrevida que, por vezes, insiste em parasitá-la.

Dois movimentos poderão nos ajudar nessa boa utopia. Em primeiro lugar, arquitetar espaços de fuga para frente: projetar uma sociedade mais justa e mais desejante, e fazê-la acontecer. Em segundo lugar, investir na fuga para dentro: exercitar a reflexividade, a autocrítica, a humildade, o desejo primeiro de ser útil à sociedade.

Levantar da cadeira é o primeiro passo para sonharmos com os nossos pés, mãos e cérebro, horizontes de fuga.

Nômade, flaneur, caminhantes, talvez sejam os atributos de um novo ser do conhecimento que quer correr o risco de pensar complexo, que quer abrir os braços para o abraço: abraçar. Esse é um sonho possível.

Basta que, como temos feito tantos de nós, não transformemos os limites invisíveis em barreiras intransponíveis.

Acredito que amanhã, ou daqui a mil anos, poderá fazer sentido as palavras de Jean Cocteau, que por enquanto estão guardadas numa "caixa de frases" que me foi dada de presente: "Não sabendo que era impossível, ele foi lá e fez".

Notas

1 Texto apresentado no Seminário "Estudos da Complexidade em Práticas Sociais", oferecido pelo Programa de Estudos Pós-graduados em Serviço Social da PUC-SP, coordenado pela professora Dra. Maria Lúcia Rodrigues. São Paulo, 21 de outubro de 1999.

2 Antropóloga; professora dos Programas de PósGraduação em Educação e em Ciências Sociais da Universidade Federal do Rio Grande do Norte; Coordenadora do Grupo de Estudos da Complexidade - GRECOM.

\section{Referências}

ALMEIDA, M. da C. Complexidade e ética como estética de vida. In: Thot. n. 73. São Paulo: Palas Athena, 2000.

ALMEIDA, M. da C. de; CARVALHO, E. de A.;

CASTRO, G. de (Orgs.). Ensaios de Complexidade.

Porto Alegre: Sulina; Natal: Edufrn, 1997. 
ALMEIDA, M. da C. de; CARVALHO, E. de A.; MORIN, E. et. al. Ética, solidariedade e complexidade. São Paulo: Palas Athena, 1998.

BOHM, D. Ciência, ordem e criatividade. Lisboa: Gradiva, 1992.

CAPRA, F. O ponto de mutação. São Paulo: Cultrix, 1982.

DURAND, G. A imaginação simbólica. São Paulo: Cultrix, 1988.

FREEMAN, D. Mundos imaginados. São Paulo: Companhia das Letras, 1998.

GLEISER, M. A dança do universo: dos mitos de criação ao Big-Bang. São Paulo: Companhia das Letras, 1997.

MORIN, E. O método III - o conhecimento do conhecimento 1. Lisboa: Europa-América, s.d.

Amor, poesia, sabedoria. Rio de Janeiro: Bertrand Brasil, 1998.

PRIGOGINE, I.; STENGERS, I.. A nova aliança. Brasília: Editora da UnB, 1991.

REEVES, H. Imagens de ação na física. In: A ciência e 0 imaginário. Brasília: Editora da UnB, 1994.

ROSNAY, J. 0 homem simbiótico - perspectivas para 0 terceiro milênio. Petrópolis, RJ: Vozes, 1997.

SAHTOURIS, E. A dança da terra - sistemas vivos em evolução: uma nova visão da biologia, Rio de Janeiro: Rosa dos Tempos, 1998.

SERRES, M. A filosofia mestiça - le tiers-instruit. Rio de Janeiro: Nova Fronteira, 1993.

VIERNE, S. Ligações tempestuosas: a ciência e a literatura. In: A ciência e o imaginário (op. cit).

WILSON, E. A unidade do conhecimento - Consiliência. Rio de Janeiro: Campus, 1999. 